\title{
IDENTIFICAÇÃO E CARACTERIZAÇÃO DOS SÍTIOS ARQUEOLÓGICOS DE REGISTROS RUPESTRES NO ASSENTAMENTO LAMEIRÃO, DELMIRO GOUVEIA-AL
}

\author{
IDENTIFICATION AND CHARACTERIZATION OF THE \\ ARCHAEOLOGICAL SITES OF RUPESTRIAN RECORDS IN \\ THE LAMEIRÃO SEATING, DELMIRO GOUVEIA-AL
}

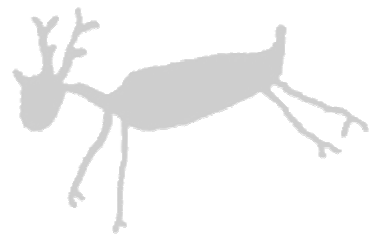

\author{
Flávio Augusto de Aguiar Moraes ${ }^{1}$ \\ flavioaguiarac@gmail.com \\ Henrique Correa da Silva ${ }^{1}$ \\ henriqueeeeee@live.com \\ José Aparecido Moura de Brito ${ }^{1}$ \\ jos.aparecido2019@gmail.com \\ Mauro Alexandre Farias Fontes ${ }^{2}$ \\ maffontes@gmail.com
}

\section{RESUMO}

Partindo do pressuposto que o revisionamento no campo arqueológico é de suma importância. O presente artigo objetivou identificar e caracterizar os sítios arqueológicos encontrados no Assentamento Lameirão, Delmiro Gouveia-AL. Para tal efeito, as análises foram feitas a partir do método de Silva (2015), que consiste em três dimensões: temática, cenográfica e técnica. Fez-se também: um georreferenciamento dos sítios arqueológicos, registros fotográficos, a altimetria. Assim, proporcionando o reconhecimento do tipo de tradição, contabilização de sítios rupestres, números de registros e comparativo entre os locais pesquisados (Sítio do Dito, Sitio Lajedo do Forró e Sítio Veredas).

Palabras clave: Lameirão, Tradição Agreste, Registros Rupestres, Delmiro Gouveia.

\footnotetext{
${ }^{1}$ Núcleo de Pesquisa e Estudos Arqueológicos e Históricos-NUPEAH/UFAL-Campus Sertão.

${ }^{2}$ Universidade Federal do Vale do São Francisco.
} 


\begin{abstract}
Assuming that the revision in the archaeological field is of paramount importance. The present article aimed to identify and characterize the archaeological sites found in the Lameirão Assen-tion, Delmiro Gouveia-AL. For this purpose, the analyzes were made using Silva's method (2015), which consists of three dimensions: thematic, scenographic and technical. It was also done: a georeferencing of archaeological sites, photographic records, altimetry. Thus, providing recognition of the type of tradition, accounting of rock sites, numbers of records and comparative among the sites surveyed (Sítio do Dito, Sitio Lajedo do Forró and Sítio Veredas).
\end{abstract}

Keywords: Lameirão, Tradition Agreste, Rock paintings.

\title{
CONTEXTO DA PESQUISA
}

Com o objetivo de classificar e ordenar as pinturas e gravuras rupestres a partir de parâmetros caracterizadores foi estabelecido para a região Nordeste do Brasil um ordenamento dos grafismos rupestres que estabeleceu a existência de quatro tradições: a Tradição Nordeste, a Tradição Agreste, a Tradição Geométrica e a Tradição Itacoatiara (GUIDON, 1985; AGUIAR, 1986; MARTIN E GUIDON, 2010; PROUS, 1992; MARTIN, 2013; PERAZZO ET AL, 2015; KESTERING, 2007; CALDERON, 1993 entre outros).

Para essa pesquisa, atentamos para a Tradição Agreste pelo fato de que os registros rupestres dos sítios pesquisados no Assentamento Lameirão, no município de Delmiro Gouveia-AL (figura 1), trazem os elementos característicos desta tradição. 

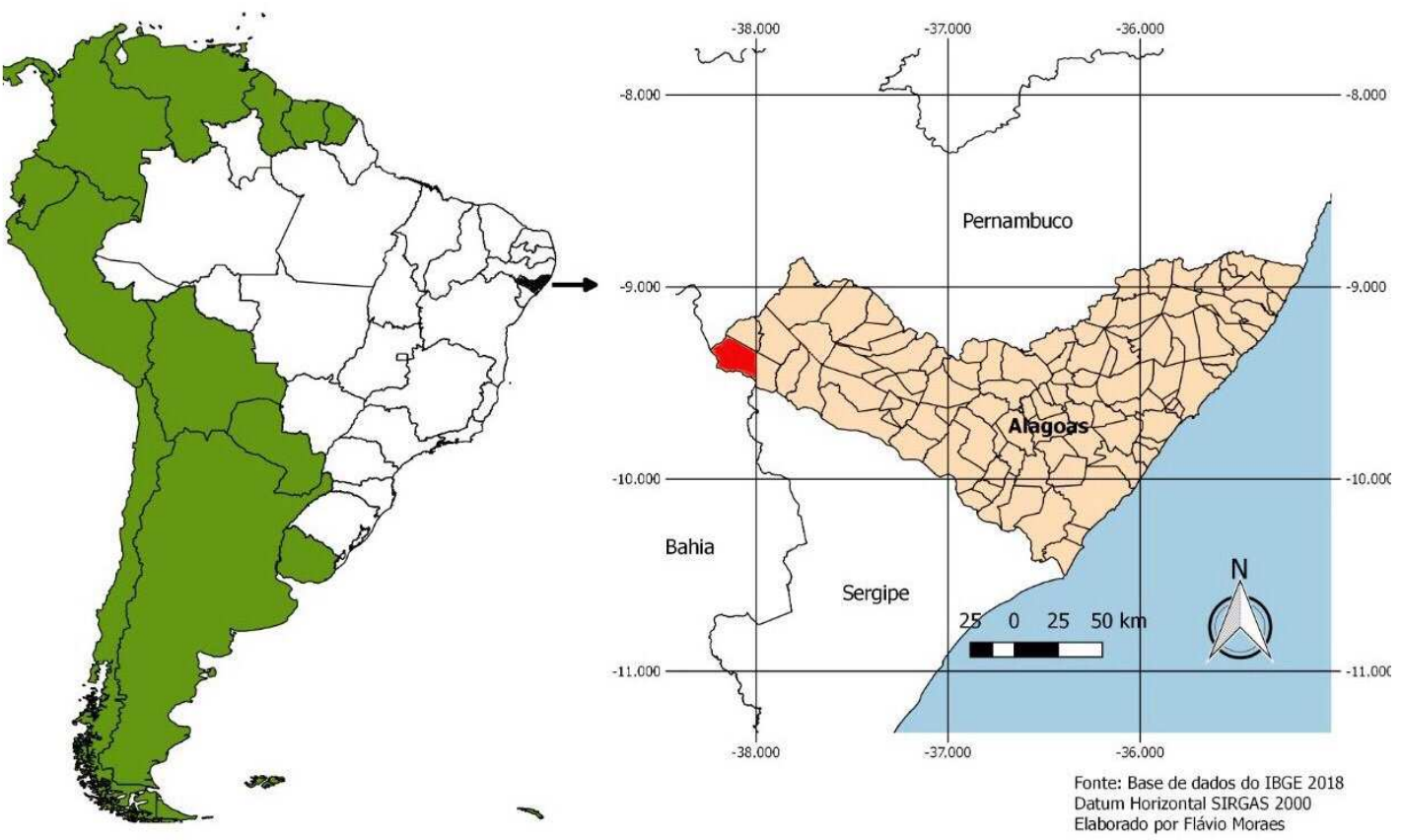

Figura 1. Localização da cidade de Delmiro Gouveia, Sertão do estado de Alagoas.

Os sítios arqueológicos aqui estudados foram identificados inicialmente pela comunidade local que vive no entorno. Moradores do Assentamento Lameirão, que desenvolvem atividades de trilha na caatinga para pessoas e grupos interessados em turismo rural, nos trechos onde os sítios estão situados, foram surpreendidos por esses afloramentos rochosos com pigmento em vermelho que apresentavam formas, especialmente zoomórficas. Esses mesmos moradores contactaram pesquisadores do Núcleo de Pesquisa e Estudos Arqueológicos e 
Históricos, que após visita técnica constatou-se se tratar de sítios arqueológicos de registro rupestre vinculado a Tradição Agreste.

A Tradição Agreste, segundo Martin (2005), foi considerada posterior à Tradição Nordeste, pelo fato de não ter datações mais antigas, tampouco um banco de dados mais completo. Contudo há datações mais recuadas para esta tradição, passando dos 30.000 anos (MARTIN, 2005; WATANABE et al., 2003). A Tradição Agreste é encontrada também em outros estados do Nordeste brasileiro: Bahia, Pernambuco, Paraíba e Rio Grande do Norte (MARTIN, 2005; MARTIN, 2013; FILHO et al., 2019).

Nesse sentido, temos a descrição de Martin (2005) acerca dos tipos de grafismos que caracterizam a referida Tradição. De acordo com a pesquisadora, as principais características da Tradição Agreste nas suas primeiras definições, foram os grafismos em maiores dimensões (entre 50 e $100 \mathrm{~cm}$ ), geralmente isolados, sem formar cenas e, quando estas existem, apresentam-se compostas por poucos indivíduos ou animais.

Ainda sobre as características da Tradição Agreste, Martin (2005) indica que é comum encontrar também grafismos que representam quelônios e lagartos. Peixes também aparecem com desenhos esquemáticos de poucos detalhes. Outro grafismo que, dependendo das regiões, é mais ou menos comum, e que pode ser considerado como emblemático desta tradição, é a figura de um pássaro de longas 
penas e asas abertas, cujo antropomorfismo sugere a representação de um homempássaro. Marcas de mãos são eventualmente encontradas, mas segundo a autora, não é de todo um elemento específico desta tradição. A Tradição Agreste apresenta figuras formadas por traços irregulares e assimétricos, com desproporcionalidade morfológica e postural, remetendo a figuras distorcidas. Assim, as figuras disformes e com ausência de acuidade técnica é o referencial cognitivo desta Tradição (AMARAL, 2014, p.66). Ao analisar, especificamente, as figuras antropomórficas da Tradição Agreste, Amaral (2014) afirmou que elas apresentam elementos que evocam o caráter humano, pois possuem os constituintes da atividade vital, mas alerta para a falta de harmonia entre as partes que as compõem, que forneceriam a estas uma identidade contra-natura. Afirma, que as posturas e gestualidade representadas no conjunto gráfico da Tradição Agreste remetem, em alguns casos, a posturas forçadas que salientam as características humanas em uma situação de desproporcionalidade. Destaca, ainda, que as figuras antropomórficas se apresentam no conjunto gráfico, majoritariamente, em projeção frontal.

Dentre os elementos gráficos presentes na Tradição Agreste, temos os grafismos que segundo Martin (2005) podem apresentar-se como simples ou elaborados, acompanhando os grafismos de ação sejam eles antropomorfos ou zoomorfos. Há a aparição de "grafismos puros labirínticos ou em formas de grades, espirais e linhas sinuosas de vários tamanhos e que, aparentemente, não guardam nenhuma relação entre si [...]” (MARTIN, 2005). 
Há também a Tradição do São Francisco que se estende pelo Vale do São Francisco, Bahia e Sergipe, Goiás e Mato Grosso. Nessa Tradição,

\begin{abstract}
os grafismos abstratos (geométricos) sobrepujam em quantidade de zoomorfos e antropomorfos [...] a utilização da bicromia é intensa nas figuras pintadas. Os raros zoomorfos são quase que exclusivamente peixes, pássaros, cobras, sáurios e talvez tartarugas. Notável ausência de cervídeos; não existe nenhuma cena, mesmo tipo, 'implícito', mas existem por vezes 'trocadilhos' entre biomorfos e sinais (região da Montalvânia) (PROUS, 1992, p.525).
\end{abstract}

Contudo, em se tratando dos grafismos puros ou irreconhecíveis, Guidon e Martin (2010) alertaram em seu artigo intitulado "A onça e as orantes" que deve haver um revisionamento em suas classificações e descrições, até porque tanto em pesquisas anteriores bem como as recentes, os pesquisadores acabaram só reproduzindo o que em outrora (1970-1980) foi estabelecido. As autoras ressaltam ainda que termos estabelecidos sem um sentido palpável era posto como demarcador de análise. Assim, afirmam as autoras;

[...] Como se este fosse o tema mais fácil da pré-história, proliferam os estudiosos, amadores, simpatizantes e curiosos da arte rupestre, sem entender que, precisamente, se trata de uma das vertentes mais difíceis e enigmáticas do registro arqueológico. Junto a trabalhos minuciosos e sérios temos lido fantasias inaceitáveis. Pássaros, lagartos e totens onde outros só viram grafismos abstratos. Cabe, aliás, perguntarmos o que seria "abstrato", "geométrico" ou 
"simbólico", para os homens que pintaram ou gravaram as rochas. (MARTIN E GUIDON, 2010, pp. 15-16. Grifos nossos)

Tendo em vista que os arqueólogos se aprofundaram mais sobre as pinturas do que sobre as gravuras rupestres, por não conseguirem estabelecer parâmetros para seu reconhecimento, cabe aqui uma descrição detalhada sobre os processos de sua construção. De acordo com Pessis (2002).

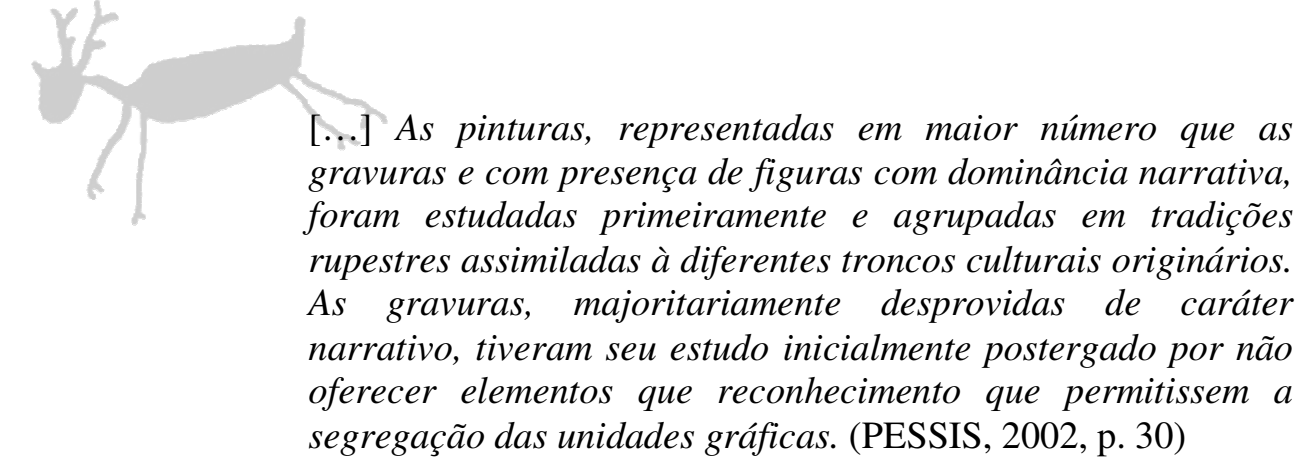

Segundo Pessis (2002) há datações de gravuras bem mais antigas do que as pinturas em sítios encontrados no continente europeu, afirma ainda a autora que em termos arqueológicos, as gravuras são os vestígios mais antigos das manifestações gráficas. Trata-se de diversos objetos gravados achados em sítios arqueológicos europeus. Pesquisas traceológicas demonstraram que as marcas gravadas achadas são intencionais e antrópicas, diferentes dos traços deixados por dentes de outras espécies. A Tradição Itacoatiara é uma tradição caracterizada essencialmente por gravuras, geralmente encontrada nas margens de rios e cursos 
d'água. Em sua maioria, composta por representações de figuras não reconhecíveis, mas com algumas raras figuras reconhecíveis como antropomorfos e zoomorfos.

Nesse sentido, é pertinente que observemos como esses registros estão organizados no suporte rochoso bem como as técnicas que foram utilizadas no processo da sua construção. As gravuras rupestres têm um processo diferente da pintura, ou seja, enquanto na pintura os grupos pretéritos usavam pincéis, as mãos, saliva, o ocre, a gordura vegetal; nas gravuras, o processo se mostrou bem complexo sendo necessária a aplicação de uma metodologia que abarque os registros em todo o painel. Segundo Pessis (2002), analisando esses fenômenos, é possível estabelecer relações e amplia o debate e reflexão, dando mais consistência às descrições.

Diante do exposto, esta pesquisa tem por objetivo caracterizar os elementos gráficos de três sítios arqueológicos identificados no município de Delmiro Gouveia, sertão do estado de Alagoas, e perceber similaridades e descontinuidades tanto nas representações gráficas como nas escolhas dos respectivos suportes onde os registros ocorrem.

\section{PROCEDIMENTOS UTILIZADOS}

Os sítios arqueológicos foram estudados enquanto unidades, sendo realizado o levantamento das dimensões do painel com registro gráficos, e caracterização e 
individualização dos elementos gráficos. Para essas atividades utilizamos uma trena, formulário contendo campos a serem preenchidos com todas as informações a serem levantadas. As informações levam em consideração as três dimensões do fenômeno gráfico estabelecidas por Pessis (1993), a saber: a temática (se os grafismos apresentavam: cabeça, tronco, pescoço, membros, patas e cauda), a técnica (o tipo de traço e o tratamento do suporte) e a cenografia (a composição, cena, medições, o quadro, o preenchimento e a coloração), bem como os conceitos de conhecível e reconhecível, abordados por Santos e Kestering (2017). Segundo esses pesquisadores, as figuras:

[...] são conhecíveis quando representam elementos do mundo concreto, conhecido pelos grupos autores das mesmas, assim como, pelos pesquisadores. Quando isso acontece, consegue-se acessar parte do significado das figuras analisadas porque se dispõe do código desvendado no contexto ambiental elou arqueológico. (SANTOS E KESTERING, 2017)

Já as reconhecíveis, "Quando não se dispõe do código que permita a interpretação [...]. Por expressarem realidades que não são conhecidas pelos pesquisadores elas são identificadas nas recorrências. (SANTOS E KESTERING, 2017).

Também realizamos um detalhado levantamento fotográfico, que nos estudos arqueológicos de um modo geral é essencial, especialmente em se tratando de sítios de registro rupestre, pois permite a obtenção de uma documentação visual, já que esse patrimônio cultural se degrada a cada dia e não é renovável. O registro 
fotográfico foi feito buscando estabelecer três parâmetros distintos de análise. No primeiro foi privilegiado o contexto ambiental onde o sítio encontra-se inserido e a configuração morfológica do mesmo. No segundo, foi registrada cada unidade gráfica presente no painel. E por fim, mas não menos importante, foi registrado bioturbações presentes na rocha, tais como casas de inseto, manchas de salitre e dejetos de animais, bem como os desplacamentos e falhas naturais, que podem contribuir no processo de degradação.

Acerca do registro fotográfico, Roskams (2001) explicita que,

[...] En un nivel puramente, también se deben tomar decisiones dificíles sobre la hora y el contenido exacto de la fotografía y la preparación para cualquer toma implicará la integración del trabajo de diferentes indivíduos. Sus actividades tienen que ser programadas de foma que el toral de un área designada sea expuesta em un momento predefinido de la investigación [...] (ROSKAMS, 2001, p.147).

Após o levantamento fotográfico e a seleção de imagens a serem utilizadas, estas foram tratadas com em software iDStretch, com o objetivo de tornar mais visível a representação gráfica analisada. 


\section{RESULTADO}

Foram visitados e realizado o levantamento em 3 sítios arqueológicos de registro rupestre, o primeiro deles, Sítio do Dito, um abrigo sob rocha com abertura para o oeste, situasse a 3 quilômetros do Assentamento Lameirão, em uma área de preservação, a qual as medidas registradas foram de $25 \mathrm{~m}$ de comprimento, 4,20 de largura e 3 metros de altura, sendo registrado 70 imagens de pinturas rupestres derivados de instrumentos e dedos das mãos com coloração avermelhada, sendo 1(um), em específico na coloração preta, que provavelmente foi feita por carvão. Nestas perspectivas, as imagens registradas com escala apresentam-se como Tradição Agreste conhecível e reconhecível (gráfico 1), tendo assimilação com figura de antropomorfo (figura 2), e representações de animais denominadas como zoomorfo (figura 3) contendo: cabeça, tronco, pescoço, membros e cauda, identificados de forma estática, isoladas e agrupadas com evidências de desgaste natural, como; desplacamento rochoso, salitre, cupim, erosão eólica, dejetos e urina de roedores provenientes da caatinga. 


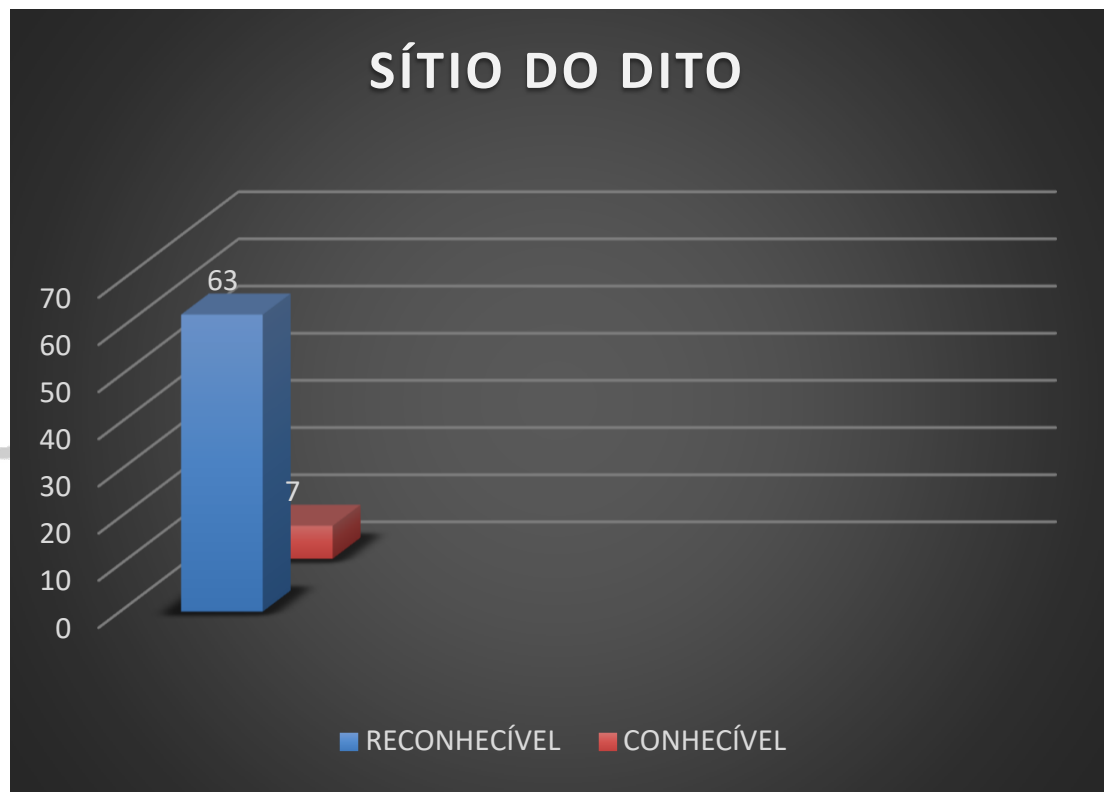

Gráfico 1.

Apresentação gráfica dos grafismos conhecíveis e reconhecíveis.

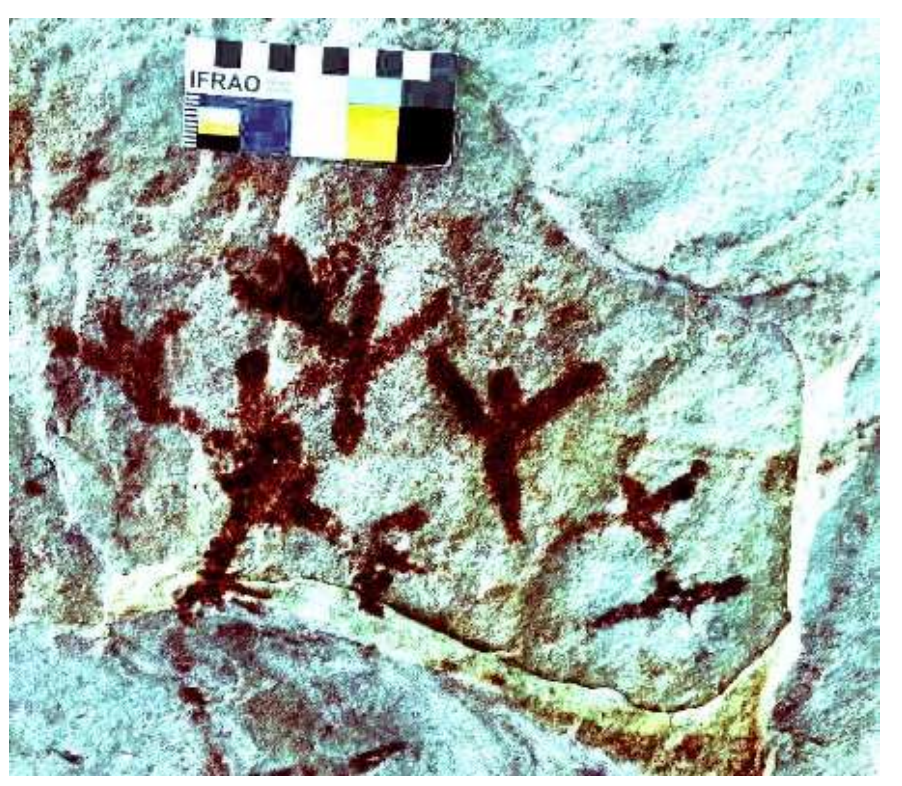

Figura 2. Antropomorfo reconhecível com braços erguidos, estático agrupado. Sítio do Dito (2019). 


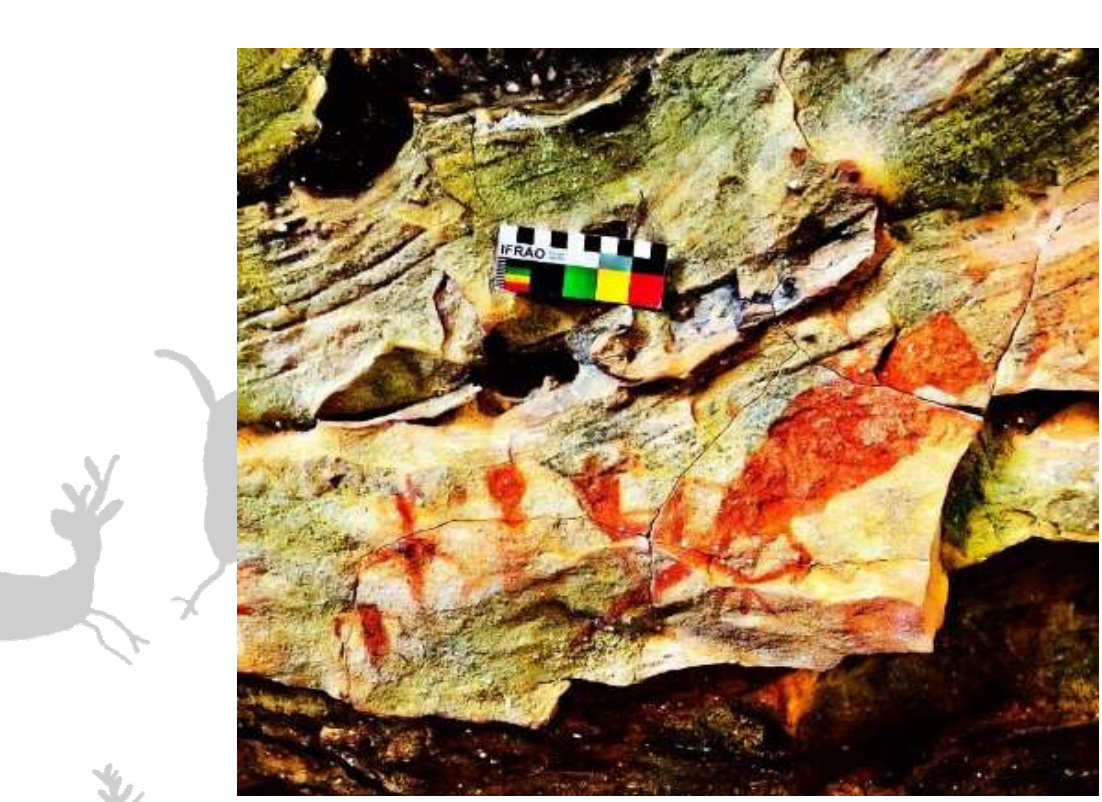

Figura 3. Zoomorfos com elementos gráficos diferentes, estático e reconhecível. Sítio do Dito (2019).

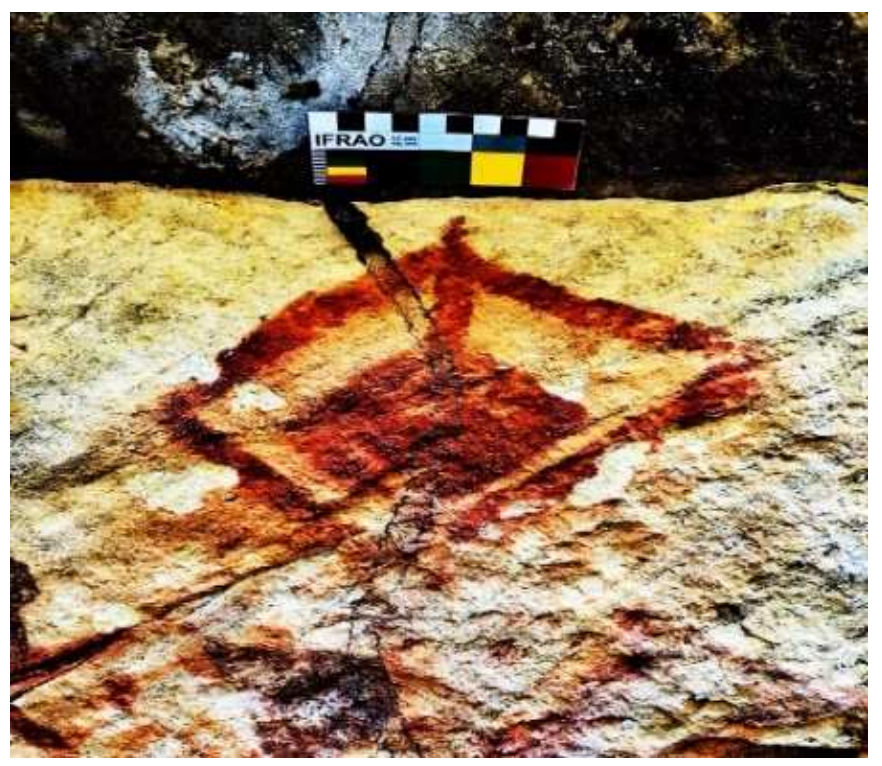

Figura 4. Grafismo puro com traços não reconhecíveis. Sítio do Dito (2019).

O segundo Sítio, também um 
abrigo sob rocha (Lajedo do Forró), está localizado a cerca de 130 m do Sítio do Dito em uma área não utilizada com dimensões de 12,80 m de comprimento, 2,20 $\mathrm{m}$ de largura e $2,30 \mathrm{~m}$ de altura foram registradas 22 imagens a qual gravuras rupestres identificadas situasse no mesmo abrigo sob rocha, onde ambos os achados foram confeccionados através de instrumentos. Assim sendo, divide-se como 16 registros de pinturas rupestres com coloração avermelhada, 5 registros de gravuras e 1 registro de uma figura identificável de um zoomorfo (gráfico2), contendo cabeça, tronco, membros, cauda e patas.

O Sítio Lajedo do Forró enquadrasse como reconhecível através da figura zoomorfo e irreconhecível (figuras 5, 6 e 7), denominado grafismo puro ${ }^{3}$, em um ambiente cenográfico agrupado e de forma estática, que por sua vez, possui erosão eólica com desgaste natural causado pelo salitre existente. Foi identificado predominância de grafismos irreconhecíveis, conforme apresentado no gráfico abaixo.

\footnotetext{
${ }^{3}$ Segundo Madu Gaspar (2006), grafismos puros são imagens desprovidas de traços que permitam identificá-los em uma representação de nosso universo sensível.
} 


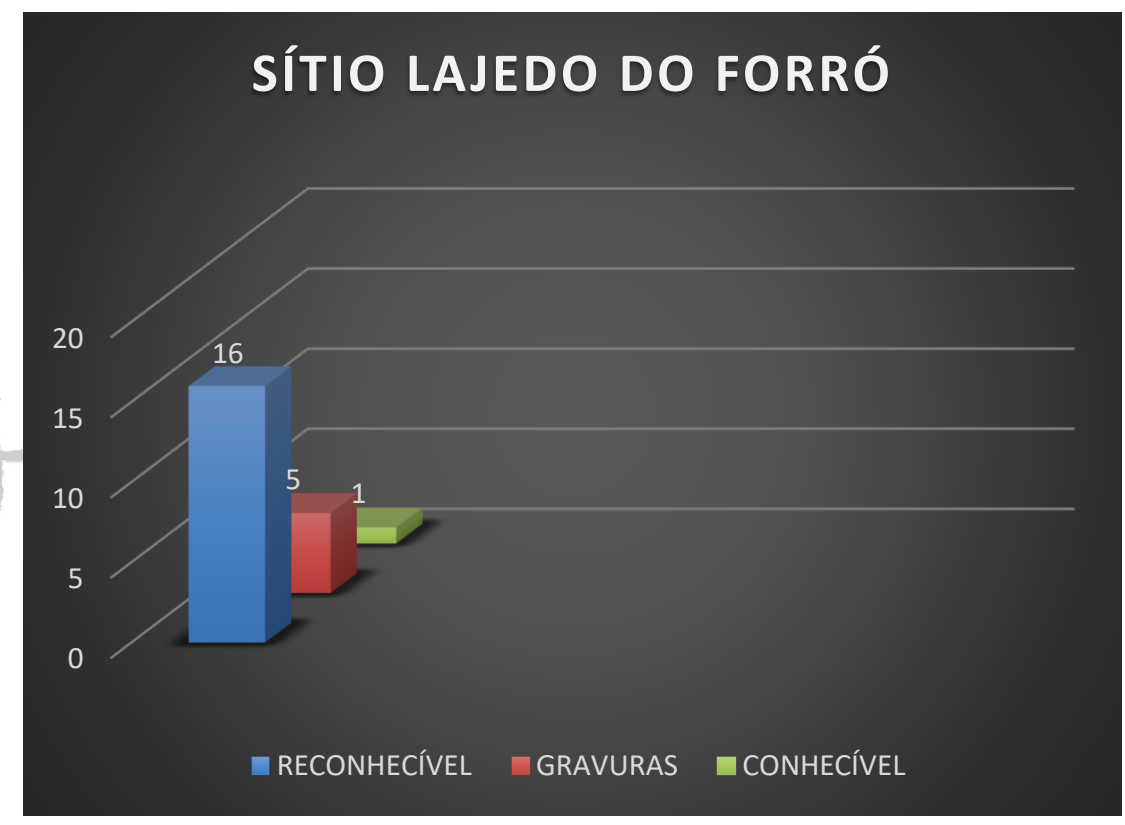

Gráfico 2. Apresentação gráfica dos grafismos e gravuras conhecíveis e reconhecíveis (2019).

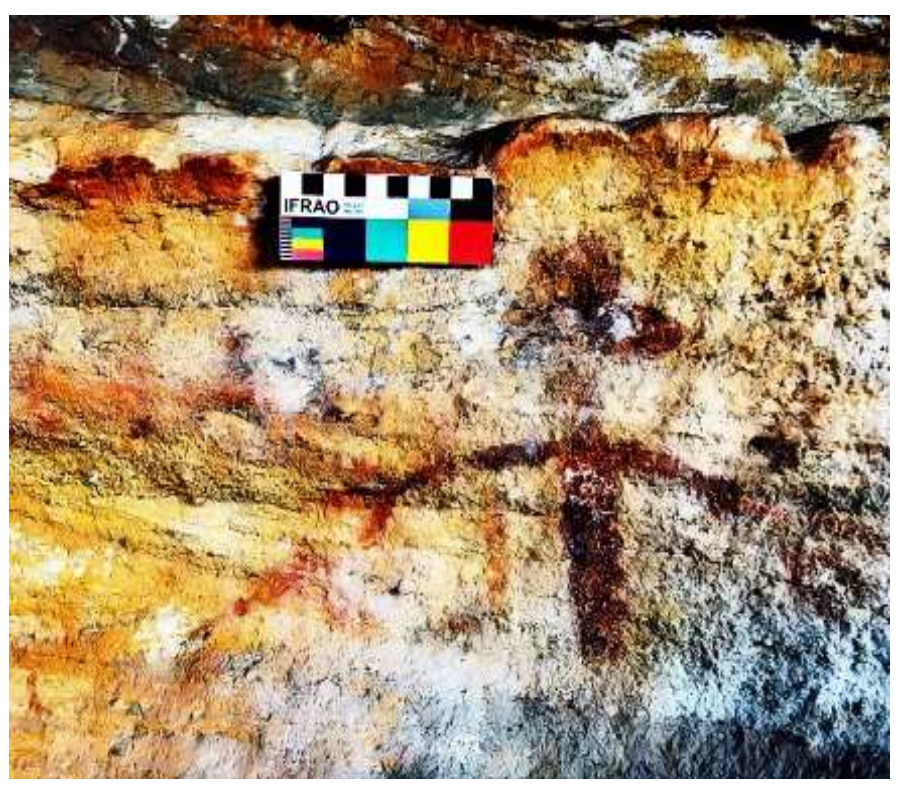

Figura 5. Zoomorfo estático e isolado. Sítio Lajedo do forro (2019). 


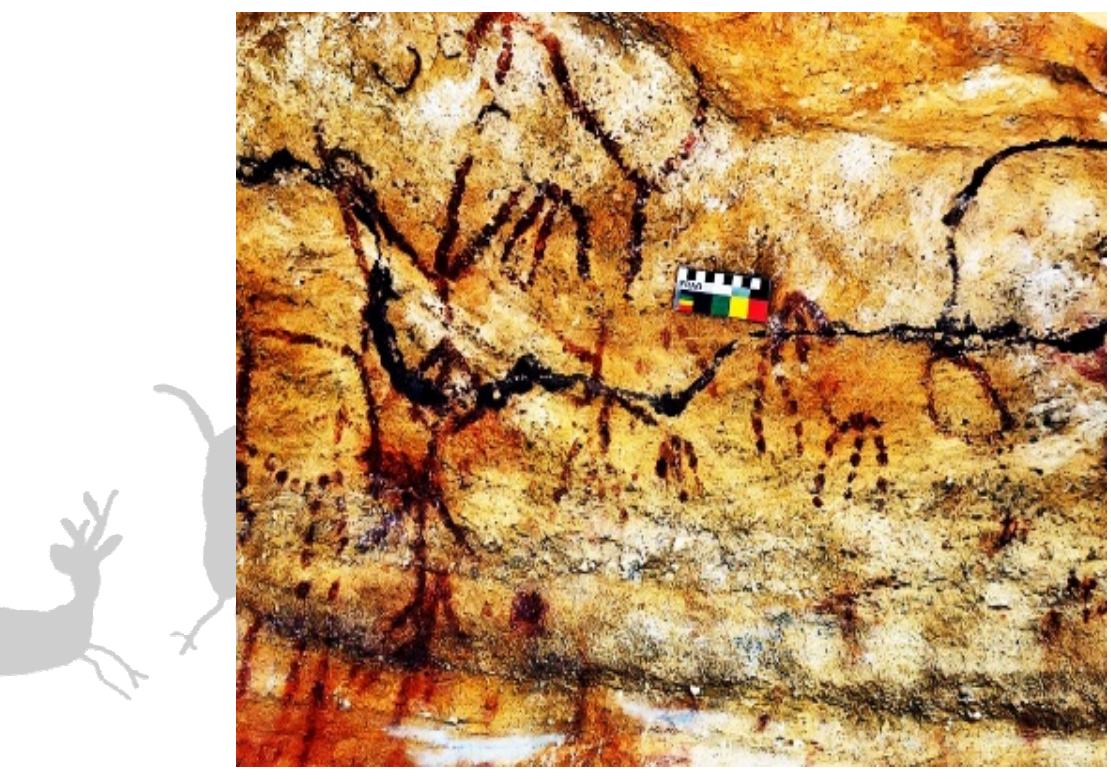

Figura 6. Grafismo Puro irreconhecível agrupado. Sítio Lajedo do Forró (2019).

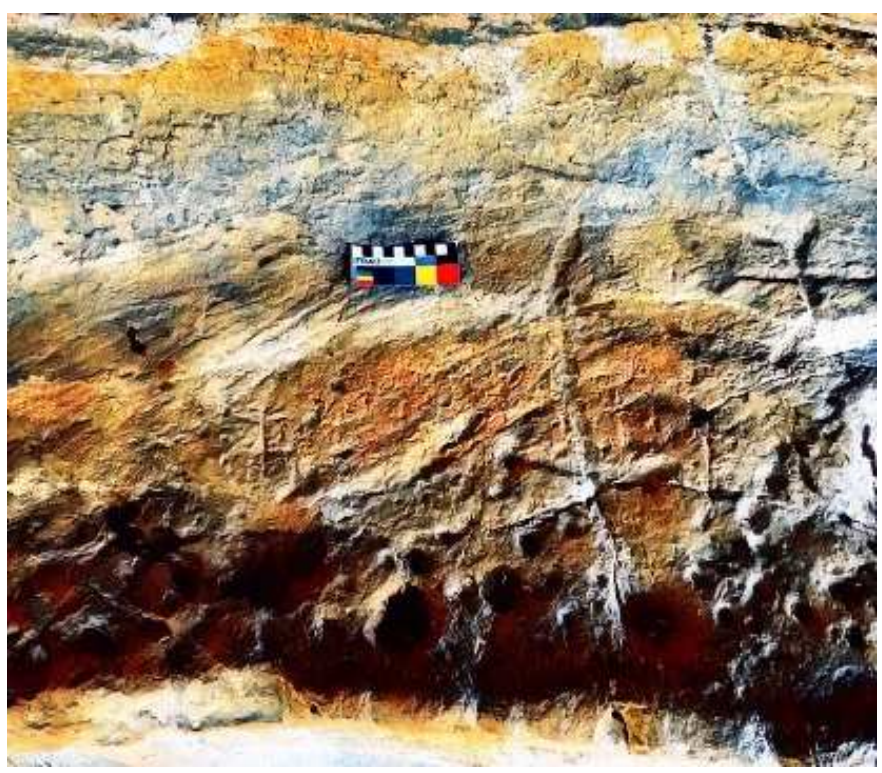

Figura 7. Gravuras rupestres irreconhecíveis agrupadas. Sítio Lajedo do Forró (2019). 
Por fim, o terceiro Sítio, denominado de sítio Veredas, situa-se e um afloramento rochoso contendo pinturas nos dois lados, sentindo $\mathrm{SO}$ e $\mathrm{NE}^{4}$, cerca de $1.300 \mathrm{~m}$ de distância dos dois primeiros sítios citados acima, sendo o lado SO com dimensão de 7,20 $\mathrm{m}$ de comprimento, 0,50 $\mathrm{m}$ de largura, e 2,0 $\mathrm{m}$ de altura.

O lado SO (Sudoeste) do abrigo sob rocha possui 3 registros de pinturas rupestres com dimensões reconhecíveis (zoomorfo) e irreconhecíveis (grafismo puro) de cor avermelhada (figura 10), caracterizado como imagens estáticas elaboradas por instrumentos e aspecto de corrosão pelo salitre presente.

O lado NE (Nordeste) apresenta dimensões de 3,30 m de comprimento, largura de 2,60 m e altura de $1,73 \mathrm{~m}$, contendo 4 registros de pinturas rupestres de forma estática na cor vermelha, isolada elaborada com instrumento, possuindo vestígios de salitre, urina de roedores nativos da caatinga (mocó) e cupim, a qual propaga no desgaste natural de algumas pinturas encontradas. As imagens analisadas na extremidade oposta à região $\mathrm{SO}$, assemelham-se as dimensões reconhecíveis, como no caso do zoomorfo do sítio Veredas (figuras 8 e 9).

\footnotetext{
${ }^{4}$ Representação da localização do Sítio Veredas através dos pontos cardeais para a caracterização da posição geográfica.
} 


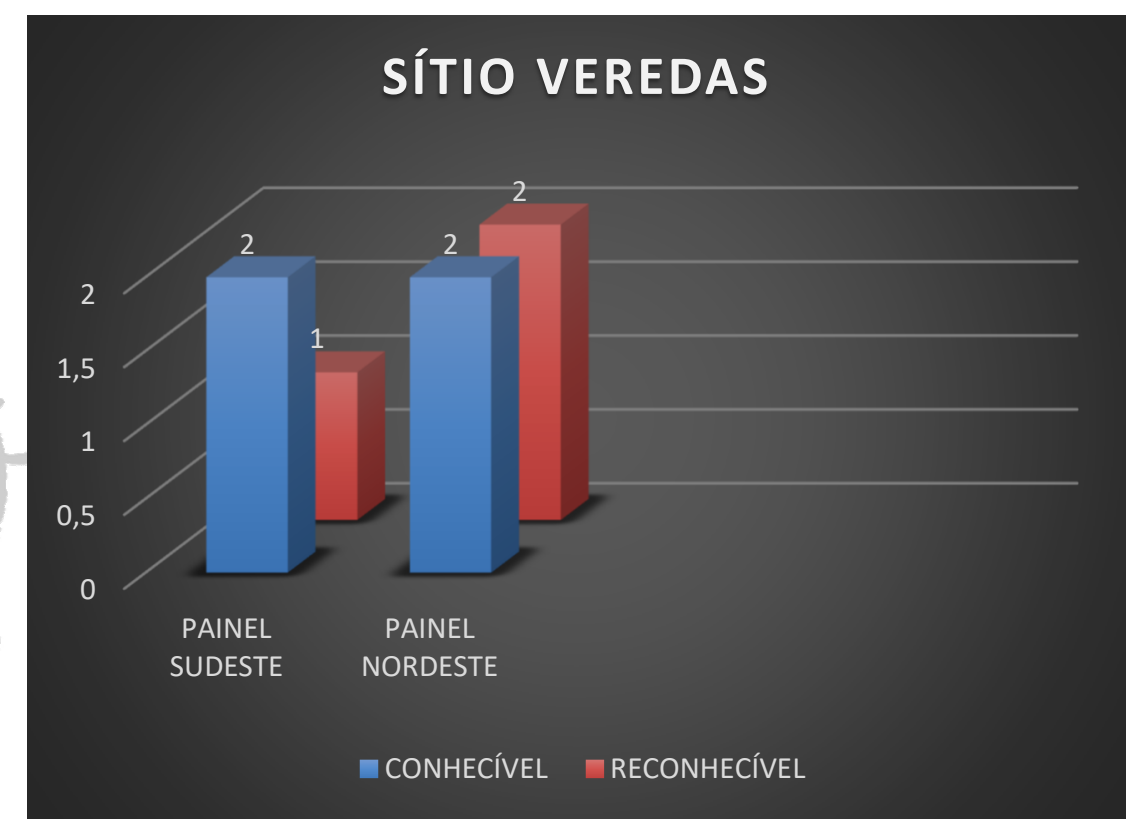

Gráfico 3.

Apresentação gráfica dos grafismos conhecíveis e reconhecíveis.

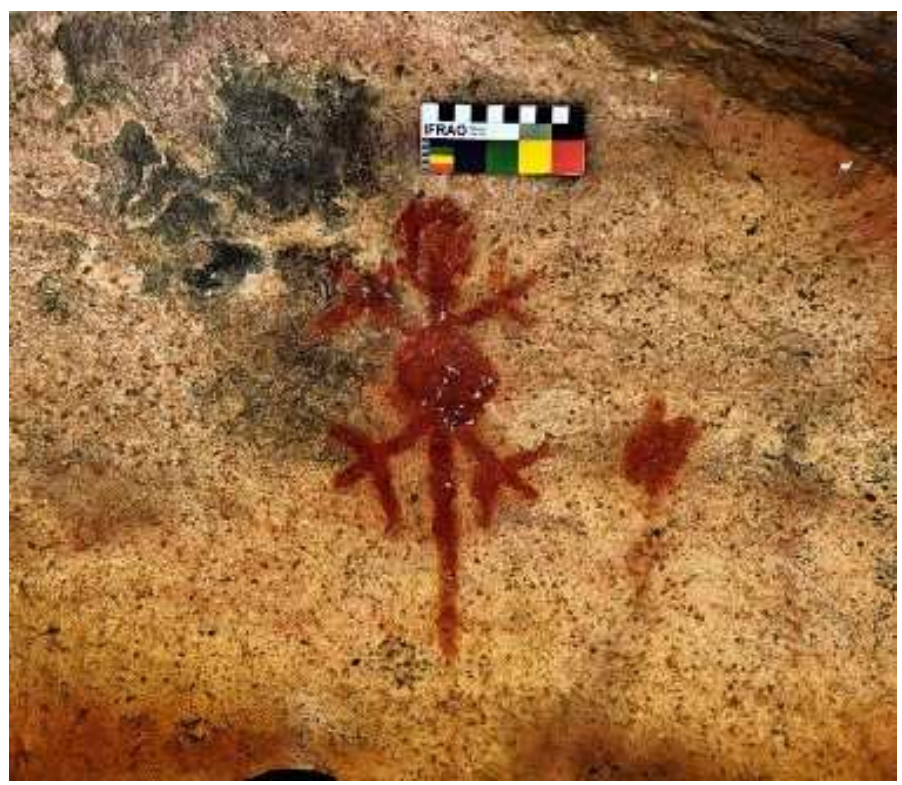

Figura 8. Zoomorfo estático reconhecível. Sítio Veredas (2019).

Indexadores: Latindex, ISIS, Google Academic 

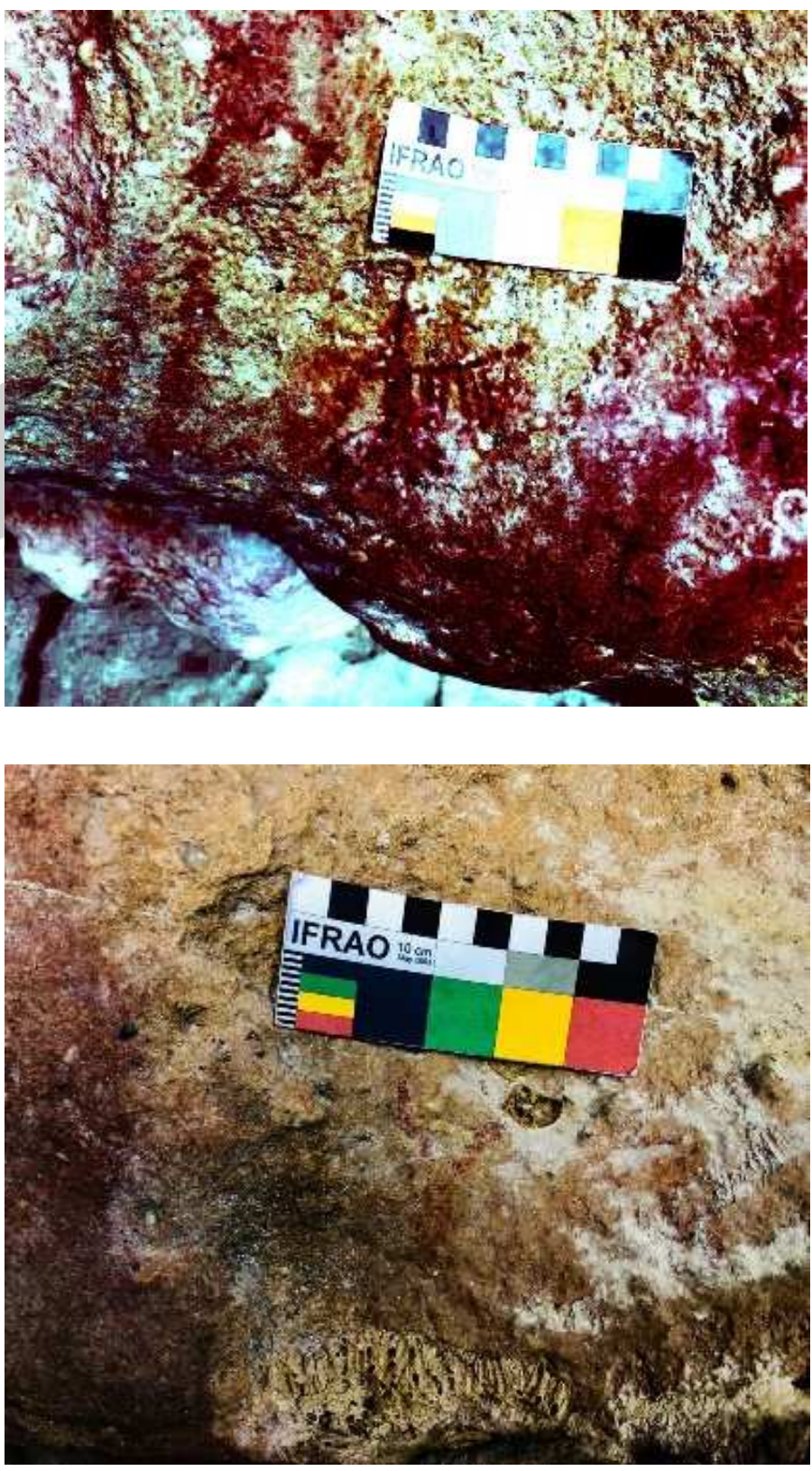

Figura 9. Imagem tratada em software (iDStretch) de zoomorfos reconhecíveis, estáticos e agrupado. Sítio Veredas (2019).

Figura 10. Grafismo puro irreconhecível. Veredas (2019). 
Em relação as condições de preservação, verificou-se que em todos os três sítios, haviam marcas de desgastes naturais como desplacamento e presença de salitre (figuras 11 e 12), intervenções antrópicas como o conjunto de blocos de rocha organizados e com marcas de queima, que muito provavelmente foi utilizado para se fazer uma fogueira na área interna do abrigo (figura 14), bem como dejetos de animais de pequeno porte, e casas de insetos (figura 13).

\section{CONSIDERAÇÕES}

Através da Arqueologia na busca da compreensão a partir da cultura material dos povos pretéritos, os registros rupestres tornam-se destaque como uma das evidências da atividade humana no passado, em uma conjuntura de que o grafismo rupestre pode ser considerado uma espécie de comunicação social entre os grupos que as realizaram.

A observação de mudanças na representação gráfica de um mesmo tema associa à distribuição geográfica que permite a distinção de subtradições, que são modificações de uma tradição, em consequência do contato dos grupos com outros tipos de ambiente (PESSIS, 1992), fato que não identificamos nos sítios ora analisados.

Nos 3 (três) Sítios Rupestres encontrados no Assentamento Lameirão, foi possível identificar mais de 93 (noventa e três) vestígios rupestres, entre pinturas e gravuras, que por sua vez, encontram-se em uma região geologicamente propícia, 
com afloramentos rochosos horizontais e verticais côncavos que serviram para as práticas gráficas, onde no Sítio do Lajedo do Forró foram encontradas gravuras em um suporte rochoso horizontal. Evidencia-se, nas representações gráficas dos três sítios analisados uma homogeneidade dessas representações, e essas similaridades podem estar atreladas a proximidades das relações simbólicas dos grupos realizadores. Um fato que pesa contra e dificulta as interpretações é a ausência de cronologia, mesmo que relativa, desses sítios.

Como se vê, existem aspectos de desgastes naturais nos 3 (três) sítios, como cupim, salitre, xixi e fezes de roedores, desplacamento rochoso e algumas evidências de interferência humana no Sítio do Dito.

Em suma os registros rupestres estão sujeitos alterações ocasionadas pelo tempo, se dando por maneiras naturais como confecção de novos grafismos nos suportes rochosos já existentes, o tipo de pigmentação (tinta) usado pode variar persistindo ou não no tempo, possibilitando ao arqueólogo a identificação a partir das diferenças gráficas, que por sua vez foi possível fazer comparativos entres os três sítios.

Observações preliminares permitem propor, em nível hipotético, que as figuras do no Assentamento Lameirão, por serem majoritariamente reconhecíveis pertençam à Tradição São Francisco. Foram realizadas por grupos pré-históricos originários 
do Planalto Central do Brasil e estabelecidos no Vale do São Francisco desde o final do Pleistoceno até períodos relativamente recentes do Holoceno.

Por apresentarem dominância temática diferente da que compõe a Subtradição Sobradinho pertencem a uma subtradição a ser definida. As figuras da temática dominante da Subtradição Sobradinho apresentam traços contínuos, em diagonal ascendente e descendente, quando horizontais, ou da esquerda para a direita e vice-versa, quando verticais. As figuras dominantes no Assentamento Lameirão representam bastonetes paralelos. A identificação de uma dominância temática diferente, relacionada com suportes de estrutura e composição geológica diferentes sugere a ocorrência de uma subtradição que não a de Sobradinho. Para que essa se comprove demandam-se outras pesquisas na região.

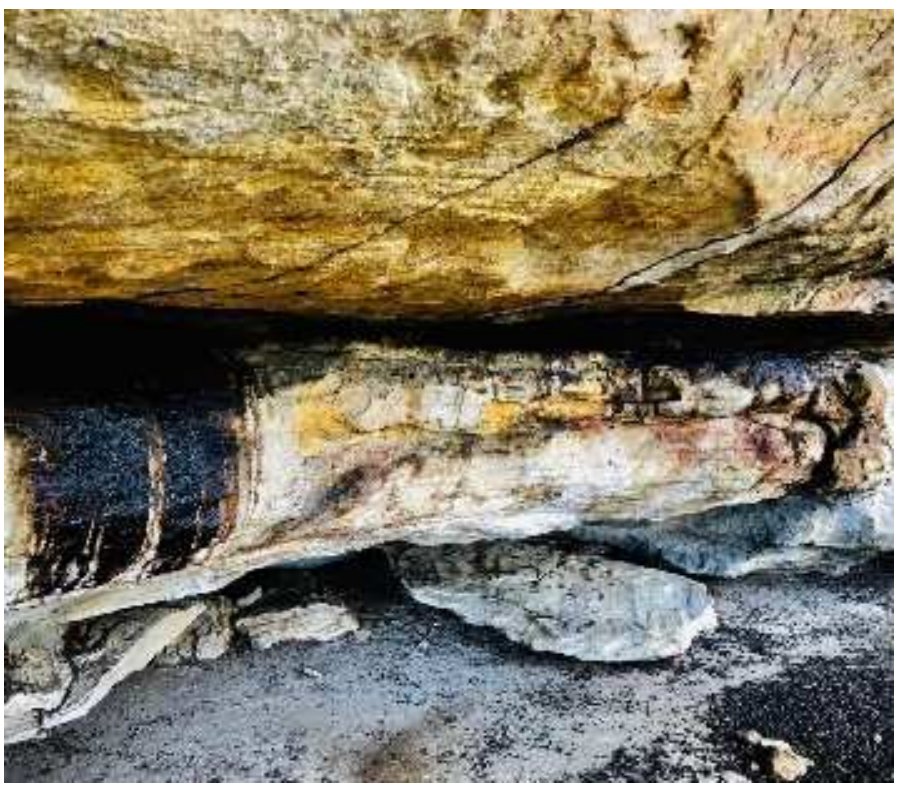

Figura 11. Sítio do Dito. Evidência de urina, fezes, cupim, salitre e fissuras rochosas.

Indexadores: Latindex, ISIS, Google Academic 


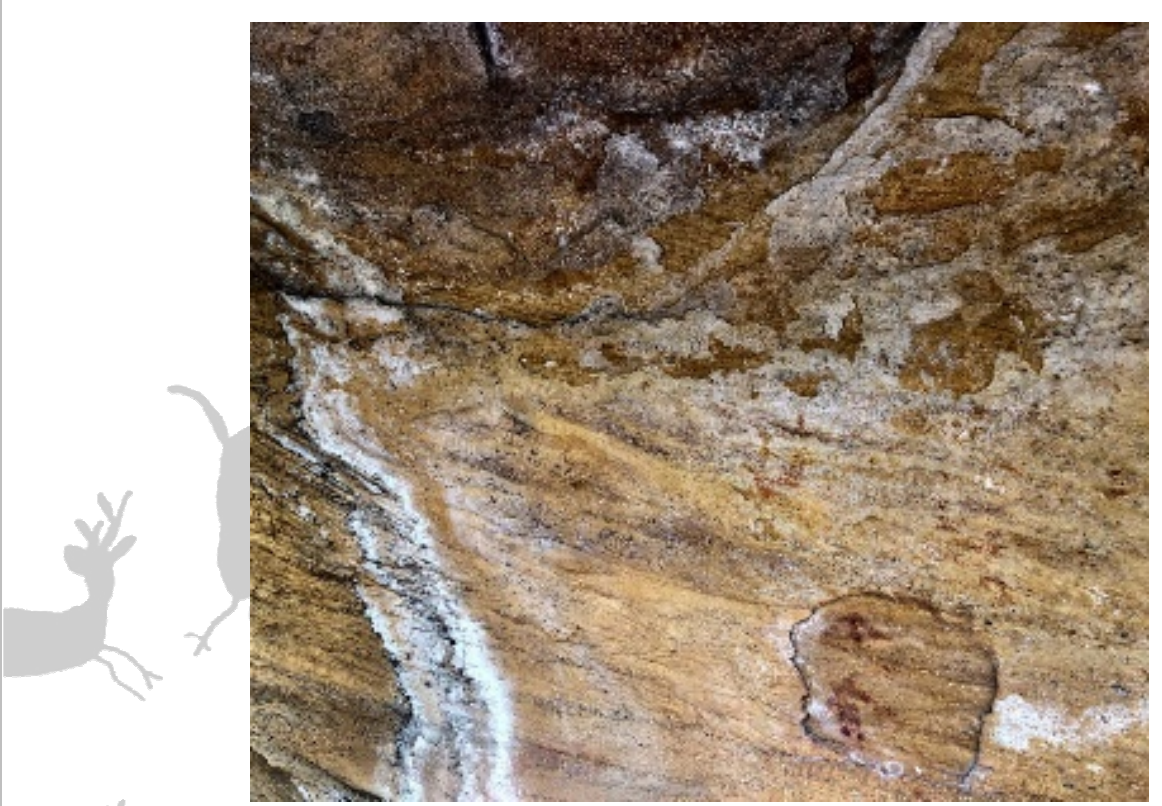

Figura 12. Sítio Lajedo do Forró. Evidência de Salitre e desplacamento rochoso.

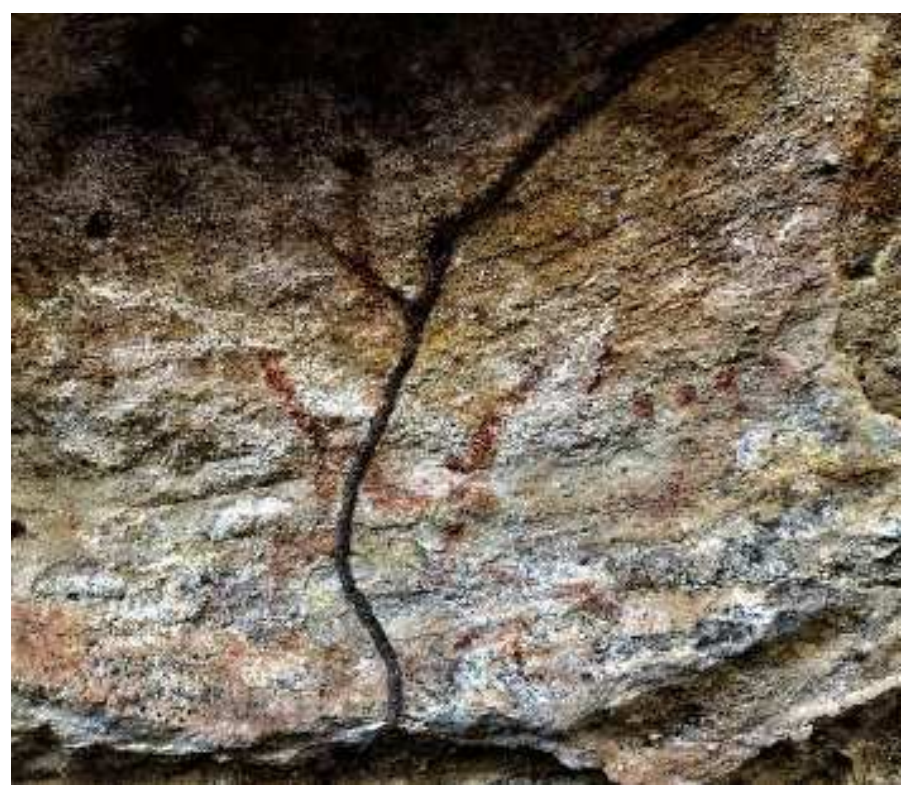

Figura 13. Sítio do Dito Evidência de cupim e salitre. 


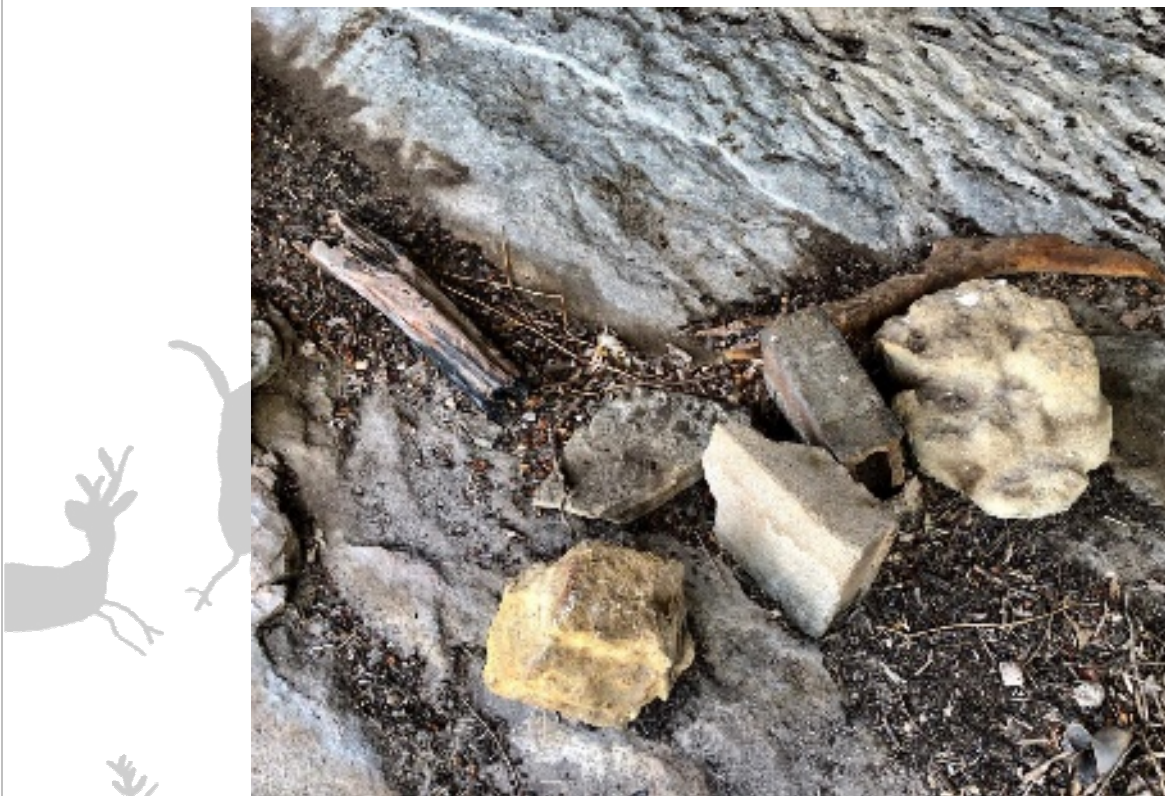

Figura 14. Sítio do Dito.

Resquício de uma fogueira.

\section{REFERÊNCIAS BIBLIOGRÁFICAS}

AGUIAR, Alice. A tradição Agreste: estudo sobre a arte rupestre em Pernambuco. https://www3.ufpe.br/clioarq/images/documentos/1986-N3/1986\%201.pdf

AMARAL, M. P. V. As pinturas rupestres da Tradição Agreste em Pernambuco e na Paraíba - Brasil. Tese (Doutorado em Arqueologia). Universidade Federal de Pernambuco. Recife, 2014.

CALDERÓN DE LA VARA, Valentin S. Estudos Arqueologia e Etnologia. - Salvador: Universidade Federal da Bahia, 1993.

FILHO et al. Caracterização das figuras antropomórficas da Tradição Agreste em Pernambuco. www.fundacaoparanabuc.org.br/arquivo/b10b3_2Noctua\%202018.2\%20Art.\%202.pdf 
GASPAR, M. A arte rupestre no Brasil. Rio de Janeiro: Jorge Zahar, 2006. 84 p

GUIDON, Niède. A arte pré-histórica da área arqueológica de São Raimundo Nonato: síntese de 10 anos de pesquisas.

https://www3.ufpe.br/clioarq/images/documentos/1985-N2/clio1985\%201.pdf

KESTERING, Celito. Identidade dos Grupos Pré-históricos de Sobradinho. UFPE. Recife. (Tese de Doutoramento). 2007.

MARTIN, Gabriela. As pinturas rupestres do sítio Alcobaça, Buíque-PE, no contexto da Tradição Agreste. https://www3.ufpe.br/clioarq/images/documentos/2005N18/2005a2.pdf

MARTIN, Gabriela. GUIDON, Niède. A onça e as orantes: uma revisão das classificações tradicionais dos registros rupestres do Nordeste do Brasil. CLIO Arqueológica. V.25. $\mathrm{n}^{\circ}$ 1. Recife, pp. 11-30, 2010.

MARTIN, Gabriela. Pré-história do Nordeste do Brasil. - 5a ed. Universitária da UFPE, 2013.

MARTINS DOS SANTOS, Raphael Godinho E KESTERING, Celito. Registros Rupestres da Toca do Gado, Município de São Gabriel - BA. 2017 En Rupestreweb, http://www.rupestreweb.info/tocadogado.html

PERAZZO, Marília et al. As pinturas rupestres da tradição agreste em Pernambuco e na Paraíba.

http://www.fumdham.org.br/wp-content/uploads/2019/03/fumdham-2-as-_376679.pdf

PESSIS, A-M. Identidade e Classificação dos Registros Gráficos Pré-históricos do Nordeste do Brasil. Revista Clio - Série Arqueológica, Recife, n. 8, p. 35-68. 1992.

Registros Rupestres, Perfil Gráfico e Grupo Social. 1993.

https://www3.ufpe.br/clioarq/images/documentos/1993-N9/1993a1.pdf

Indexadores: Latindex, ISIS, Google Academic 
PROUS, André. Arqueologia Brasileira. - Brasília, DF: Editora Universidade de Brasília, 1992.

ROSKAMS, Steve. Teoría y práctica de la excavación. Crítica Barcelona, 2001.

WATANABE ET AL. Some evidence of date of first humans to arrive in brazil. Jornal of archaeological sicence. pp. 351-354. 2003

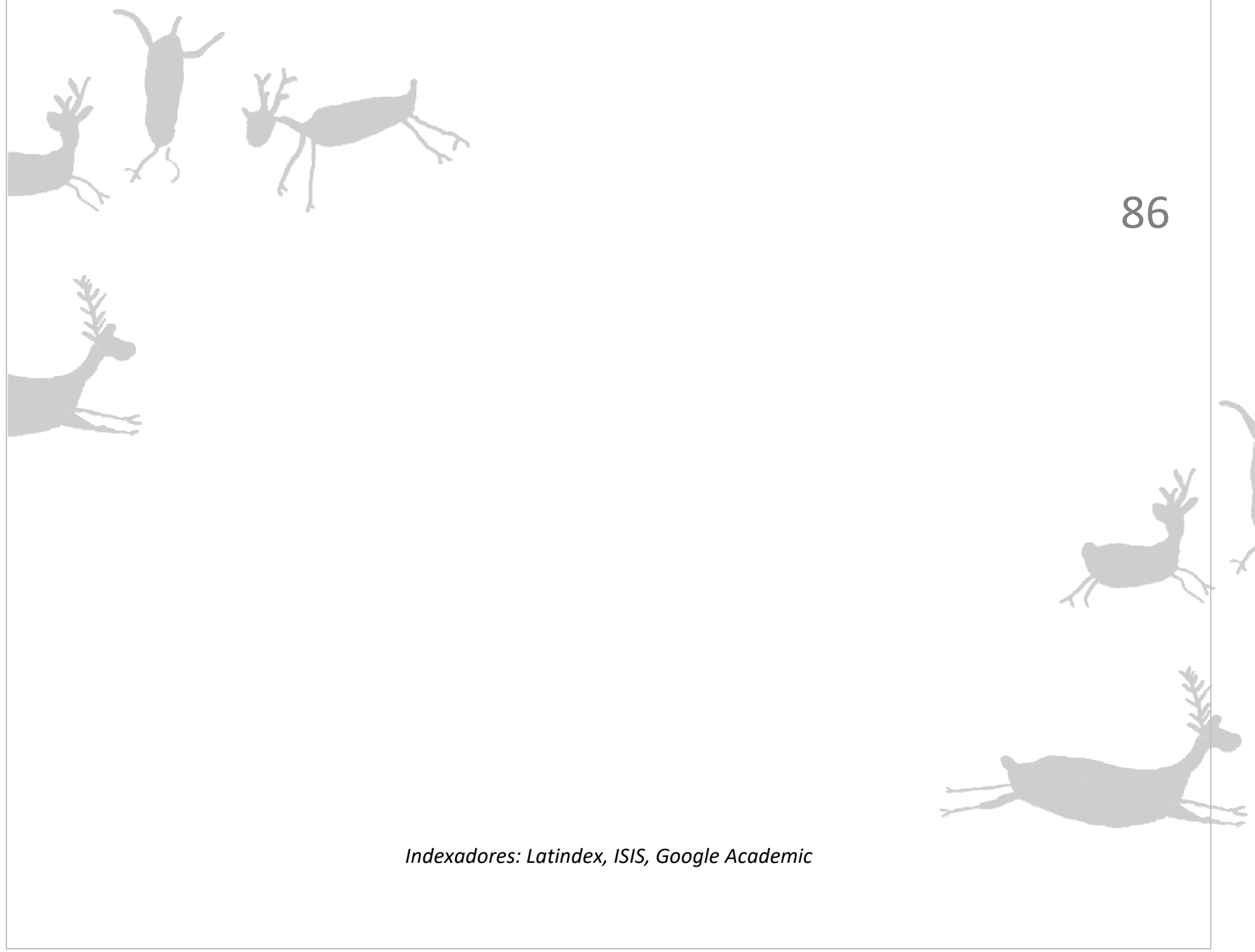

